\title{
Make (A Wish upon the Stars) - Handcraftsmanship Work and New Generations, an Arising Love Affair, Hand in Hand
}

\author{
Alberto Campagnolo* \\ Visiting Professor, Fujen Catholic University, Taiwan
}

*Corresponding author: Alberto Campagnolo, Post graduate Visiting Professor, Fujen Catholic University, Taiwan.

Received Date: April 28, 2020

Published Date: May 13, 2020

Abstract

There is no apparel and accessories luxury without exceptional human and technical skills. Nowadays it is evident that - after the recent economic crisis - also the Covid-19 pandemic is profoundly reshaping the meaning and the goals of the "fashion education" term, as well as of its professional landscape. Many are the signals for a new promising dawn, from the DIY to the recent academies founded by several fashion brands that want to push the envelope in the direction of the "trans-generational" passage excellent tradition. The role of "hand-made" and "made in" is more and more seductive for the millennial and the new generations that may meaningfully find a gateway towards the luxury and the fashion world. There is a "manual intelligence" that is fairly and finally rediscovered. Like in the culinary world, also in fashion the manual work is achieving a new glamour and even coolness, maybe unexpected but full of potential. How can fashion brands and academies ride this trend in order to give an extra boost to their engagement and rejuvenation process?

\section{Opinion}

Many are the signs that demonstrate a remarkable revival of interest in manual professional activities. Although creativity has always coincided with the physical realization of a thought (during the Renaissance, when artists were "geniuses of making", as well as after the Second World War, where "art" and "craftsmanship" were considered two sides of the same coin), since the 1970s there has been a neat discrepancy between the figure of the creative (the mind) and the one of the creator (the hands). Undoubtedly because of socio-political requirements (in 1968 all over the world people shouted "we want to think" to affirm a speculative urgency of particular expression more intellectual and less linked to the consumer society), a crack between thought and action has occurred. All of this also influenced the context of education, with more or less "exclusive" school courses depending on the emphasis placed on either speculative thinking or manual skills. The grandes écoles, focused on a notional and intellectual culture; and the technical institutes, often relegated to secondary school.
On the other hand, the dimension of manual work is starting to become very fascinating today, especially among the youngest. In different directions, nowadays the signals coincide and trace a crystal-clear trend. The so popular acronym "DIY" (stands for do-it-yourself) testifies to the growing demand for independence that is not only aesthetic, but also creative. The opening of several manual laboratories allows people to devote time and resources to learn not only a profession, but also a true "culture of making". Not to mention the popular TV programs like Master Chef, Bake Off and related trends among the youngest. In September 2019 in Cologne, German GenZ celebrated the "Tag of Handworks" (the day of manual labour), where almost 20,000 young people celebrated and expressed in the streets their pride in working with bare hands.

As always, the fashion world has anticipated this trend. The technique is more and more visible in shop windows, permanent museums and traveling exhibitions, in the videos that each house publishes on YouTube. Ermenegildo Zegna highlights the 
experience and excellence of the "who does what" through their displays (showing both hands and weaving of frames). All Saints Spitalfields found in sewing machines the symbol of their own creative uniqueness, beyond their productive artefact. Inside the latest itinerant exhibitions of Louis Vuitton, artisans explain visitors some of the excellent techniques for making leather goods, an artistic moment of absolute value that deserves admiration and consideration as an artwork. Pride in "making". The contribution of the hand (the human touch, the personal approach, conferring uniqueness to their creations) is fundamental to preserve the meaning and sense of a universe that owes its existence to the concept of uniqueness.

Hands, instruments of creation and creative derivation of a thought. The driver of "made in" says a lot about the pride of using the hands as well as the brain. As if the attention of the "made in" was diverted from the simple geographical area to give value to the "made", to the fact in itself. Already in 2011 Prada had anticipated this trend in a visionary way, no longer promoting the country of origin of the brand, but instead the excellence of the manufacture of specific clothing made where the best producers in the world are located (India for embroidery, Scotland for cashmere, Japan for denim, etc.). In addition, in the past year, major fashion companies such as Gucci (with its Ecole de l'amour as part of the Art Lab), Dolce \& Gabbana (with their Botteghe di mestiere) and Brunello Cucinelli (with his Scuola di Solomeo) (Figure 1) have opened their academies within their headquarters in order to teach youngsters how much "making things happen" has a huge value. To pass on a technical knowledge that risks to be lost, to explain the difference between being an atelier and being a brand. There is no coincidence even in these pandemic times: one of the first professional activities in fashion that reopened after the lockdown on April 20th, 2020 was the Gucci Art Lab, building specifically conceived for the sharing of fashion knowledge and its handicraft practicing (Figure 1).

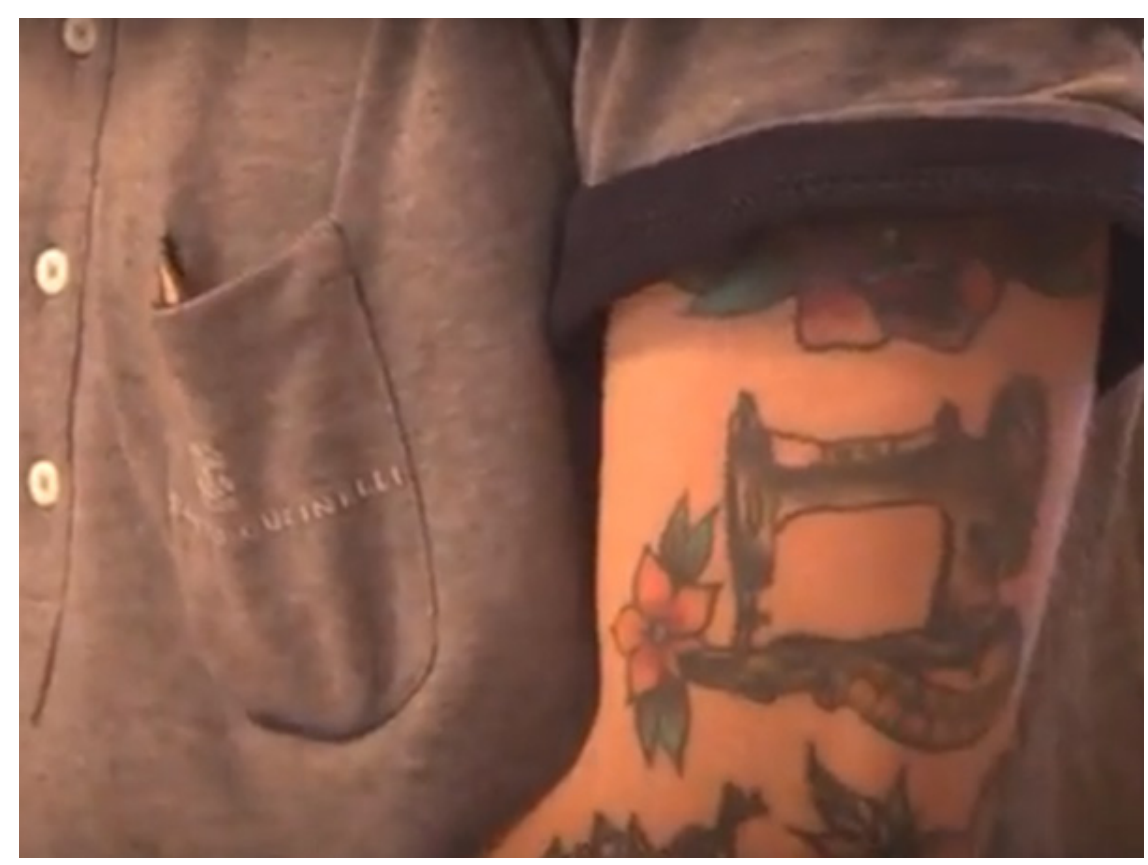

Figure 1: https://www.youtube.com/watch?v=ZatVk94JZrl.

The recent imposed restrictions put in force in Italy (where all the above-mentioned academies are located, to demonstrate a very specific genius loci spirit as always so peculiar there) as well as in other countries, clearly demonstrated the limits of the digital lifestyle among the GenZ regarding the fashion culture. Stuck at home in front of their cell phones, somehow saturated against the grain (a good example, again, of the booming of self-made food at home during the worldwide quarantine), with flour and yeast impossible to find in the grocery stores, youngsters are now thirsty of practical activities, and whatever is linked to a sensory experience is now highly desirable to them. Fashion remains a holistic dimension where the meaning comes from perceiving ourselves throughout senses, including touch and smell. Figuring out how to play show rooming for shopping while in quarantine sounds almost revolutionary. Nevertheless, every artification phenomenon post Covid-19 will result from these new impulses, therefore fashion has definitely a huge potential in the reshaped expression of the handcraftsmanship contribution. Creativity that starts from restrictions is always powerful. Besides new safety requirements that will obviously arise, the "places of making" will be perfect layers of expression, of artefact creation, of teamwork. GenZ guys cannot wait to restart rolling up their sleeves.

Creative and creators work hand in hand then, literally. Even in an era of globalisation and mass production, the world of fashion and specifically luxury needs expert artisans. But such knowhow must always be matched with creativity and the culture of the project in order to compete within a fast-evolving world. 
There is a precious intelligence and wisdom in our hands. Growth opportunities, both in the academic and professional context, are really interesting. Creative and creators will be able to interact more closely as the manual activity is perceived to be cooler: less competitive and academic, more reassuring and rewarding. The next arising trend about GenZ is that they will not consider relevant to simply create, but to recognize themselves in their creations, to put their footprints in the making process.

\section{Acknowledgement}

None.

\section{Conflict of Interest}

None. 